Revista Oficial del Poder Judicial

ÓRGANO DE INVESTIGACIÓN DE LA CORTE SUPREMA DE JUSTICIA DE LA REPÚBLICA DEL PERÚ

Vol. 11, n. ${ }^{\circ} 13$, enero-junio, 2020, 439-458

ISSN versión impresa: 1997-6682

ISSN versión electrónica: 2663-9130

DOI: https://doi.org/10.35292/ropj.v11i13.53

\title{
Trabajo remoto en procesos no urgentes a consecuencia del brote del coronavirus (COVID-19) en el Perú y su aplicación continua
}

The coronavirus outbreak and the Remote work implementation for not urgent Judicial Processes, the Peruvian case 0 (웅

FANY MAVEL TAPIA COBA

Corte Superior de Justicia de La Libertad

(Trujillo, Perú)

Contacto: ftapiac@pj.gob.pe

https://orcid.org/0000-0002-2981-7503

\section{RESUMEN}

El presente artículo es el resultado de la búsqueda de la modernización de la administración de justicia y el despacho judicial, dada la coyuntura generada a raíz de la propagación de la COVID-19 y el aislamiento social ocasionado por esta. Así, se brindan soluciones efectivas para la continuidad de la tramitación de los procesos no urgentes, cuya finalidad inmediata es la implementación del trabajo 
remoto para la descarga procesal y cuya finalidad mediata es la aplicación continua y progresiva de este.

Se espera que el trabajo remoto se divulgue y se replique como herramienta de trabajo durante el estado de emergencia, con reglas que se adapten a casi todos los procesos tramitados en el Poder Judicial, en los distritos que no cuenten con el Expediente Judicial Electrónico.

Palabras clave: COVID-19, trabajo remoto, procesos no urgentes.

\section{ABSTRACT}

This article gives an overview of the implementation of remote work system that have transformed the judicial system during the context of coronavirus outbreak. The implementation of Remote work serves to optimize the procedural discharges of not urgent Judicial Processes.

It is perceived that remote work is relevant to the Judicial Court optimization and it can be adapted in the places where an Electronic Judicial Expedient is not available.

Key words: remote work, justice system, Electronic Judicial Expedient.

Recibido: 25/05/2020 Aceptado: 08/06/2020

\section{EL CORONAVIRUS O LA COVID-19 CAUSANTE DEL CAMBIO DE ESTILO DE VIDA}

El fenómeno del virus surgió en China y, a mediados del mes de enero de 2020, los médicos alemanes Rothe, Schunk, entre otros (2020), refirieron:

El nuevo coronavirus (2019-nCov) de Wuhan actualmente está causando preocupación en la comunidad médica a medida que el virus se está extendiendo por todo el mundo. Desde la identificación 
del virus a fines de diciembre de 2019, el número de casos de China que se han importado a otros países está en aumento y la imagen epidemiológica está cambiando a diario (p. 970).

El transporte de pasajeros a nivel mundial permitió la propagación del virus; de esa manera llegó a América Latina. En el Perú, el Poder Ejecutivo dictó el Decreto Supremo n. ${ }^{\circ}$ 008-2020-SA, de fecha 11 de marzo de 2020, el cual declaró la emergencia sanitaria a nivel nacional por el plazo de noventa (90) días calendario, y dispuso diversas medidas de prevención y control destinadas a evitar la propagación de la COVID-19.

Dichas medidas han resultado insuficientes, puesto que, de acuerdo con las cifras estadísticas publicadas por el Ministerio de Salud en la aplicación «Perú en tus manos», al 25 de mayo de 2020, existen 123979 casos confirmados, lo que demuestra su constante crecimiento.

Según las investigaciones realizadas:

La vía de transmisión más probable del COVID-19 es por contacto y gotas respiratorias (aerosoles), en distancias cortas $(1.5 \mathrm{~m}) \mathrm{y}$ también por fómites contaminados por dichos aerosoles. No puede descartarse completamente que exista cierto grado de trasmisión por vía aérea. El contacto prolongado es el de mayor riesgo, siendo menos probable el contagio a partir de contactos casuales (Trilla, 2020, p. 176).

Como se aprecia, los contagios no solo se pueden determinar por personas sintomáticas, sino también por las asintomáticas, realidad que obliga a buscar alternativas de trabajo, sobre todo en el Poder Judicial, como poder estatal encargado de administrar justicia e impedir que se genere una anarquía. 


\section{BASE LEGAL DECRETADA POR EL PODER EJECUTIVO EN EL ESTADO DE EMERGENCIA}

a) Decreto Supremo n. ${ }^{\circ}$ 008-2020-SA, de fecha 11 de marzo de 2020, que declaró la emergencia sanitaria a nivel nacional por el plazo de noventa (90) días calendario, y dispone diversas medidas de prevención y control destinadas a evitar la propagación de la COVID-19.

b) Decreto Supremo n. ${ }^{\circ}$ 044-2020-PCM, de fecha 15 de marzo de 2020, que declara el estado de emergencia nacional por el plazo de quince (15) días calendario y dispone el aislamiento social obligatorio (cuarentena), por las graves circunstancias que afectan la vida de la nación a consecuencia del brote de la COVID-19.

c) Decreto Supremo n. ${ }^{\circ}$ 051-2020-PCM, de fecha 27 de marzo de 2020, que prorroga el Estado de Emergencia Nacional declarado mediante el Decreto Supremo n. ${ }^{\circ}$ 044-2020-PCM, por el término de trece (13) días calendario, a partir del 31 de marzo de 2020.

d) Decreto de Urgencia n. ${ }^{\circ}$ 026-2020, de fecha 15 de marzo de 2020, que establece diversas medidas excepcionales y temporales para prevenir la propagación de la COVID-19 en el territorio nacional.

e) Resolución Ministerial n. ${ }^{\circ}$ 072-2020-TR, publicada en el Diario Oficial El Peruano el 26 de marzo de 2020, que aprueba el documento denominado «Guía para la aplicación del trabajo remoto».

\section{ACTUACIÓN DEL CONSEJO EJECUTIVO DEL PODER JUDICIAL}

Desde hace varios años, se ha buscado la modernización del Sistema de Justicia en el Poder Judicial, por lo que, a través del Consejo Ejecutivo, se han habilitado planes pilotos, entre los cuales se halla el Expediente Judicial Electrónico que se maneja en la ciudad de 
Lima, y en Cajamarca y Tacna; a su vez, existe la implementación de la oralidad en los procesos civiles.

Durante el estado de emergencia, el Consejo Ejecutivo ha emitido una serie de resoluciones administrativas. Para la elaboración del presente artículo, destacamos las siguientes:

a) Resolución Administrativa n. ${ }^{\circ} 010$-2014-CE-PJ, de fecha 7 de enero de 2020, que aprueba el Reglamento Interno de Trabajo del Poder Judicial y sus modificatorias.

b) Resolución Administrativa n. ${ }^{\circ}$ 090-2018-CE-PJ, de fecha 14 de marzo de 2018, que aprueba el Reglamento de Organización y Funciones de las Cortes Superiores de Justicia que operan como Unidades Ejecutoras.

c) Resolución Administrativa n. ${ }^{\circ}$ 103-2020-CE-PJ, de fecha 11 de marzo de 2020, que aprueba el Plan de Prevención del Coronavirus (COVID-19) en el Poder Judicial.

d) Acuerdos n. ${ }^{\circ} 480-2020$ y n. ${ }^{\circ} 481-2020$ del Consejo Ejecutivo del Poder Judicial, de fechas 17 y 20 de marzo de 2020, respectivamente, por los cuales se precisa la conformación y competencia de los órganos jurisdiccionales de emergencia a nivel nacional.

e) Resolución Administrativa n. ${ }^{\circ}$ 121-2020-CE-PJ, de fecha 17 de abril de 2020, que establece la suspensión de plazos procesales y administrativos, dispuesta por el Consejo Ejecutivo del Poder Judicial como consecuencia del estado de emergencia nacional.

f) Acuerdo n. ${ }^{\circ} 482-2020$ del Consejo Ejecutivo del Poder Judicial, por el cual se aprueba el uso de la solución empresarial colaborativa denominada Google Hangouts Meet en los órganos jurisdiccionales y administrativos del Poder Judicial, hasta que permanezca la emergencia sanitaria declarada en el país. 


\section{FORMAS ALTERNATIVAS DE DESPACHO JUDICIAL TRADICIONAL}

Habiéndose emitido el Decreto de Urgencia n. ${ }^{\circ}$ 026- 2020, el Decreto Supremo n. ${ }^{\circ}$ 010-2020-TR y la Resolución Ministerial n. ${ }^{\circ} 072$ 2020-TR, publicada en el Diario Oficial El Peruano el 26 de marzo de 2020, que aprueba el documento denominado «Guía para la aplicación del trabajo remoto», es imprescindible realizar un análisis de este y su envergadura en tanto forma alternativa de administrar justicia en nuestro país.

\subsection{Definición de trabajo remoto}

El origen del trabajo remoto se remonta al año 1973, cuando un exingeniero de la NASA se planteó la posibilidad de trabajar de manera remota para evitar el exceso de tráfico y los problemas de consumo de energía. Los primeros intentos de promover la idea del trabajo remoto en los Estados Unidos incluyeron el artículo de 1979 del Washington Post, «Trabajar en casa puede ahorrar gasolina», el proyecto piloto de teletrabajo entre agencias de 1992 entre las agencias gubernamentales y proyecto de ley de 2004 en el Congreso de los Estados Unidos que fomentó el trabajo remoto en las agencias federales (De Carlo, 2017, párr. 2).

Este siguió en crecimiento dentro del gobierno americano, y se expandió al sector privado, de modo que, a la fecha, la población utiliza dicho mecanismo alternativo de trabajo.

De hecho:

en un estudio reciente realizado por la empresa Buffer en conjunto con Workfrom, Hubstaff, Trello y Doist nos devela datos interesantes:

- El primer dato destacado que nos encontramos dentro de este estudio es que el 43 \% de la población activa de Estados Unidos trabaja de forma remota (Jonay, 2018, párrs. 10-11). 
El mismo autor estima que en el año 2035 habrá mil millones de nómadas digitales en el mundo.

\subsection{Nuevos retos en la administración de justicia}

La propagación de la COVID-19 nos enfrenta a una nueva realidad que ya no se puede ver como una tendencia a futuro. En principio, entendemos que el trabajo remoto se caracteriza por la prestación del servicio subordinado con la presencia física del trabajador en su hogar o lugar de aislamiento domiciliario utilizando los medios o mecanismos que le posibiliten realizar las labores atendiendo a la naturaleza de estas.

En el caso del Poder Judicial, se trabaja con los expedientes físicos en casi la mayoría de los distritos judiciales y, a su vez, se maneja el Sistema Integrado Judicial. Dicha labor se puede realizar mediante el uso de medios informáticos (telecomunicaciones), sin requerir la presencia física del personal jurisdiccional ni administrativo, así como de los litigantes.

\section{PROPUESTA DE TRABAJO REMOTO EN LOS PROCESOS NO URGENTES PRESENTADA ANTE LA CORTE SUPERIOR DE JUSTICIA DE LA LIBERTAD}

Ante los retos presentados con la continuación de las actividades jurisdiccionales de aquellos procesos no considerados urgentes y que no se encuentran comprendidos en las resoluciones emitidas por el Consejo Ejecutivo, la suscrita —en calidad de magistrada coordinadora del Módulo Corporativo de Paz Letrado Civil Comercial de Trujillo- presentó ante la Presidencia la propuesta de trabajo denominada Protocolo de Actuación de Trabajo Remoto en el Módulo Corporativo de los Juzgados de Paz Letrado Civil Comercial de la Corte Superior de Justicia de La Libertad (CSJLL) durante el estado de emergencia nacional, a consecuencia del brote del coronavirus (COVID-19) en el Perú y su aplicación continua. 
Este proyecto fue aprobado el 4 de mayo del presente año, a través de la Resolución Administrativa n. ${ }^{\circ}$ 176-2020-P-CSJLL-PJ, y fue publicado como noticia en la página web del Poder Judicial, se enfatizó que es el primer distrito judicial en brindar operatividad en los procesos judiciales en materia civil-comercial.

Sin transgredir las normas dictadas por el Poder Ejecutivo, la Superintendencia de Banca y Seguros y el Poder Judicial, e ir reiniciando paulatinamente las actividades económicas en aplicación de normas establecidas en el Código Civil y el Código Procesal Civil se establecen las acciones de acuerdo con los procesos que se tramitan en los Juzgados de Paz Letrado Civil Comercial que se precisará en el siguiente apartado.

\section{PAUTAS GENERALES DEL SERVICIO DE ADMINISTRACIÓN DE JUSTICIA BRINDADO POR EL MÓDULO CORPORATIVO DE JUZGADOS DE PAZ LETRADO CIVIL COMERCIAL DE LA CORTE SUPERIOR DE JUSTICIA DE LA LIBERTAD (CSJLL)}

El módulo referido comprende dos pautas generales:

a) En las labores jurisdiccionales y administrativas, prima el uso de las diversas herramientas tecnológicas disponibles para las comunicaciones y coordinaciones, y se evita realizar actividades presenciales, salvo en los casos excepcionales dispuestos.

b) Para el retiro de expedientes físicos, los jueces y el personal jurisdiccional y administrativo que se encuentren dentro del alcance del presente protocolo deberán usar, con carácter obligatorio, los implementos de seguridad y las medidas de prevención y control sanitarias emitidas por el Consejo Ejecutivo del Poder Judicial y el Ministerio de Salud. Para tal efecto, vía correo electrónico o WhatsApp, deberán reportar y comunicar inmediatamente a la Coordinación de Seguridad 
cualquier sospecha de síntomas o diagnóstico relacionado con la COVID-19. Asimismo, usarán un sistema de red privada virtual para conectarse con la red de comunicaciones de la CSJLI y, de esa manera, acceder a los sistemas, aplicativos informáticos y demás recursos que solo se encuentran operativos desde la red interna.

\section{PAUTAS GENERALES DEL SERVICIO DE ADMINISTRACIÓN DE JUSTICIA APLICABLE A TODOS LOS PROCESOS NO URGENTES}

Ante este contexto, el Poder Judicial ha emitido la Resolución Administrativa n. ${ }^{\circ}$ 0121-2020-CE-PJ, de fecha 17 de abril de 2020, que establece, en el tercer considerando, la suspensión de plazos procesales y administrativos respecto del usuario judicial; sin embargo, no se impide que se continúe el trámite de los procesos iniciados donde no se vulnere el debido proceso y el derecho de defensa de las partes.

\subsection{Demandas}

a) Para la digitalización de demandas nuevas, estas serán presentadas debidamente escaneadas por los abogados litigantes, en formato PDF, y serán enviadas al correo electrónico de la jefa del Centro de Distribución General para su asignacion virtual aleatoria entre los Juzgados y Secretarías respectivos. Los abogados y las partes asumirán la responsabilidad civil y penal si se acredita la adulteración de algún medio probatorio.

b) Además de los requisitos formales (artículos 130 al 133 del Código Procesal Civil), las firmas de la parte ejecutante/demandante y de su abogado deben encontrarse debidamente escaneadas o se debe contar con la firma digital electrónica validada por el sistema de Reniec. 
c) Adicionalmente a los requisitos del artículo 424 del Código Procesal Civil, el ejecutante deberá señalar su número de celular y su dirección de correo electrónico.

d) Los certificados de vigencia de poder de las entidades ejecutantes serán verificados a través del Lector de Código QR (Sunarp).

e) En caso de presentación de Título Ejecutivo (artículo 688 del Código Procesal Civil), deberá ser escaneado, y el ejecutante y su abogado deberán declarar bajo juramento que el escaneado presentado es fiel a su original y que asumen la responsabilidad civil y penal si se prueba que ha existido adulteración.

f) El pago de los aranceles judiciales debe realizarse a través de la plataforma virtual del Banco de la Nación denominada: págalo.pe, la cual expide en formato PDF la respectiva constancia del pago de los aranceles judiciales, cédulas de notificación, etc.; para ello, se dejará el link del instructivo respectivo en el FP de la Corte Superior de Justicia de La Libertad.

g) Las demandas que no han sido calificadas por los magistrados y se encuentran sin proyecto de resolución, obran en poder y custodia de los secretarios judiciales, quienes, al inicio del trabajo remoto, deberán escanearlas a través de la aplicación Office Lens y deberán remitirlas a través de la aplicación WhatsApp o correo electrónico de los magistrados.

h) De declararse la improcedencia de la demanda en etapa de calificación, se notifica dicha resolución mediante la casilla electrónica y el correo señalado.

i) De existir apelación y de ser el caso, se concede, y su elevación al superior jerárquico queda supeditada a la aprobación de los Juzgados Especializados Civiles. 


\subsection{Trámite}

a) El secretario elabora el proyecto de mandato ejecutivo o admisorio, se envía a través del SIJ para su aprobación y se comunica al juez vía telefónica; acto seguido, el juez aprueba su registro en el SIJ y ordena la corrección del proyecto.

b) Para la notificación de la demanda que se debe realizar en el domicilio real del ejecutado, esta se sujetará a las resoluciones administrativas que expida el Consejo Ejecutivo en las próximas semanas.

c) En el caso de haberse contestado la demanda o formulado contradicción, excepciones procesales, defensas previas o cumplimiento de la obligación, el secretario debe computar los plazos, teniendo en cuenta la suspensión de plazos ordenada por el Consejo Ejecutivo, previa verificación de la cédula de notificación.

d) Respecto a la contestación de la demanda o la contradicción, se corre traslado a las partes procesales. En estos casos, si ambos tienen casilla judicial electrónica o correo sin que exista un medio probatorio de actuación inmediata, no se afecta la suspensión de plazos, salvo que las partes deseen comparecer virtualmente.

\subsection{Audiencias virtuales mediante La aplicación Hangouts Meet}

a) Habiendo aprobado el Consejo Ejecutivo el uso de la plataforma Hangouts Meet, en los procesos en que es necesario fijar audiencia única, audiencia de pruebas o una audiencia especial, se señala fecha y hora para la audiencia.

b) Se envía al correo electrónico y al celular de los justiciables el link de acceso a la audiencia virtual. 
c) Los justiciables y el secretario judicial deben conectarse quince minutos antes, para la verificación de identidad respectiva y probar tanto el audio como el video; y, una vez instalada, se comunicará al magistrado para que se conecte a la audiencia.

d) La audiencia será grabada y se desarrollará conforme a las reglas de la materia de cada proceso, siempre dirigidas por el juez del órgano jurisdiccional. Cualquier incidencia que requiera ser comunicada por escrito, dentro de la audiencia o como consecuencia inmediata de esta, será transmitida por medio electrónico o conforme lo disponga el juez.

e) Concluida la audiencia, el personal jurisdiccional asignado por el juez elaborará el acta correspondiente, la asociará al Sistema Integrado del Poder Judicial y remitirá la copia de la grabación al correo electrónico de los justiciables.

\subsection{Actuación de medios probatorios}

a) En los medios probatorios que requieran actuación especial (como en el caso de pericias), se procede a designar un perito aleatorio a través del SIJ (su casilla, correo y celular obra en el SIJ); además, el secretario judicial o las partes que ofrecen los medios probatorios darán fe de la veracidad de los documentos bajo juramento.

b) De haberse admitido como medio probatorio la pericia grafotécnica, esta será actuada sobre el medio probatorio previamente digitalizado, el cual deberá ser remitido por el secretario judicial al correo electrónico o la casilla electrónica de los peritos judiciales designados por el SIJ.

\subsection{Procesos para sentencia o auto final}

a) En caso de las sentencias y autos finales, aplicando el sistema remoto y contando con la firma digital como una medida eficaz 
en la lucha contra la falsificación documentaria, la resolución se asociará en el Sistema Integrado del Poder Judicial y se realizará la notificación con arreglo a ley, conforme ordene el Consejo Ejecutivo del Poder Judicial y utilizando mecanismos alternativos de comunicación y notificación implementados en el presente protocolo, tales como el correo electrónico y la comunicación vía telefónica.

b) En el caso de concederse el recurso de apelación, la elevación pendiente queda suspendida hasta la aprobación del protocolo de Juzgados Especializados Civiles.

\subsection{Etapa de ejecución de sentencia o auto final}

a) Se podrá continuar con el proveído de escritos pendientes y dictarse medidas cautelares, como embargos en forma de inscripción, e incluso implementar el remate judicial electrónico que ya se encuentra regulado en el Código Procesal Civil.

b) Mientras dure el estado de emergencia, quedan suspendidas las actuaciones fuera de juzgado, como inspecciones o lanzamientos.

\section{TRATAMIENTO DE LAS MEDIDAS CAUTELARES INGRESADAS ANTES DE DICTARSE EL ESTADO DE EMERGENCIA}

a) En mérito a la Resolución del Superintendente Nacional de los Registros Públicos n. ${ }^{\circ}$ 240-2019-Sunarp/SN, de fecha 18 de septiembre de 2019, que regula la presentación, trámite e inscripción del título conformado por el parte judicial con firma digital sobre medidas cautelares, mecanismo que se aplicará válidamente con todas las medidas cautelares presentadas antes de que se dicte el estado de emergencia, ello mediante la firma digital, que otorga la misma validez y eficacia jurídica que la firma manuscrita, de acuerdo con el principio de 
equivalencia funcional, conforme al procedimiento establecido en el artículo 7 de dicha resolución.

b) Usar como mecanismo de agilización del trámite y transparencia el Sistema de Intermediación Digital, contenido en la Resolución del Superintendente Nacional de los Registros Públicos n. ${ }^{\circ} 120-$ 2019-Sunarp/SN, de fecha 27 de mayo de 2019, que regula el Sistema de Intermediación Digital de la Sunarp para la generación, presentación, trámite e inscripción del Título Electrónico ante el registro, evitando los fraudes procesales y anotaciones de embargos en forma de inscripción y anotaciones de demanda.

c) Suspensión de plazos de medidas cautelares que impliquen el desplazamiento de los servidores jurisdiccionales o usuarios; dada la situación de emergencia, se concederían o efectuarían al levantarse el estado de emergencia.

\section{TRATAMIENTO DE LOS PROCESOS ÚNICOS DE EJECUCIÓN. PRECISIONES POR ESTADO DE EMERGENCIA}

a) El Título Ejecutivo (artículo 688 del Código Procesal Civil) deberá ser presentado escaneado, el ejecutante y su abogado deberán declarar bajo juramento que el escaneado presentado es bajo responsabilidad civil y penal, en caso se pruebe que ha existido adulteración.

b) El presente protocolo será aplicado tanto para procesos iniciados como para el posible ingreso de demandas con títulos ejecutivos cuyas liquidaciones se hayan realizado hasta el mes de febrero, antes de la declaración del estado de emergencia.

c) En cuanto a la presentación de nuevas demandas, debe tenerse en consideración lo señalado por la Superintendencia de Banca, Seguros y AFP (SBS) en el Oficio Múltiple n. ${ }^{0}$ 5345-2010-SBS, de fecha 5 de febrero de 2010, en el que se precisa la facultad de 
las empresas del sistema financiero de efectuar modificaciones en los contratos de créditos que no obedezcan a dificultades en la capacidad de pago de los prestatarios, a efectos de que no sean considerados como refinanciaciones. Dicha directiva se aplica a la cartera de créditos, se detalla que se requiere que los deudores no hayan presentado atrasos al momento de la declaratoria de emergencia.

\section{INICIO, TRÁMITE Y EJECUCIÓN DE PROCESOS NO CONTENCIOSOS}

La reactivación de la economía del estado de emergencia y la magnitud de decesos como consecuencia del brote del coronavirus (COVID-19) en el Perú obligan a tener los mecanismos de justicia necesarios ante los decesos producidos, que van a originar las inscripciones o rectificaciones de partidas de defunción y el inicio de sucesiones intestadas específicamente en lo que respecta a procesos no contenciosos, cuya mecánica de trabajo es la siguiente:

a) En cuanto a los procesos no contenciosos, como su nombre lo indica, no existe conflicto de intereses; por tanto, es viable el inicio, trámite y ejecución de los procesos donde no exista ningún tipo de oposición.

b) El Módulo Corporativo en caso de inscripciones y rectificaciones de partidas cuenta con el proyecto denominado Rectifícate al Toque, aprobado por Resolución Administrativa n. ${ }^{\circ}$ 1002-2019-P-CSJLL/PJ, y es pasible de iniciar, tramitar, resolver y ejecutar todo electrónicamente, con cooperación del Reniec.

c) En los procesos no contenciosos (como es el caso de las sucesiones intestadas), se tramitan electrónicamente, a través de la cooperación interinstitucional de Registros Públicos, Beneficencia Pública, y, en el caso de oposición, se puede 
realizar la audiencia virtual si están plenamente identificados todos los herederos forzosos y, de surgir alguna imposibilidad por suspensión de plazos, no se vulnerará el derecho de defensa de la parte afectada.

d) En caso de consignaciones judiciales, pueden realizarse a través de los certificados digitales y deberán remitirse al protocolo de atención de estas.

e) De ser necesaria alguna diligencia que no se pueda manejar a través de las plataformas virtuales (como sería una inspección en algunos casos de facción de inventario), queda suspendido el plazo hasta el levantamiento del estado de emergencia o cuando las partes pueden brindar videos de los mismos.

\section{COORDINACIONES INTERNAS}

a) Respecto a la presentación de requerimientos, la coordinadora del órgano jurisdiccional de emergencia y la Coordinación de Informática efectuarán las precisiones electrónicas para el adecuado funcionamiento del trabajo remoto.

b) La Gerencia de Administración Distrital y la Jefatura de Unidad Administrativa y de Finanzas garantizarán la operatividad logística, de transporte, limpieza y de los demás servicios básicos indispensables para el funcionamiento de los órganos jurisdiccionales de emergencia. Asimismo, efectuarán el cumplimiento de la «Guía para la aplicación del trabajo remoto» y las disposiciones emitidas por el Consejo Ejecutivo del Poder Judicial, sobre la materia, a los trabajadores de los órganos jurisdiccionales de emergencia, administradores y demás servidores involucrados.

c) A través de la Coordinación de Informática, se verificará la operatividad o funcionamiento de los equipos, la red y los sistemas informáticos institucionales, se mantendrán comunicaciones 
constantes con el personal de los órganos jurisdiccionales de emergencia y el administrador respectivo, a fin de garantizar un efectivo monitoreo.

d) A través de la Coordinación de Estadística e Informática, se monitoreará la producción del trabajo remoto.

\section{ATENCIÓN AL USUARIO}

a) El abogado o las partes podrán efectuar la consulta sobre el proveído de escritos y el estado de los procesos judiciales a través de la habilitación de la línea telefónica cuyos datos se registrarán en el FP de la Corte Superior de Justicia de La Libertad. Dicha atención será registrada en el Libro Virtual de Atención al Usuario.

b) Se programarán las citas con los magistrados mediante entrevistas digitales si lo consideran necesario las partes o sus abogados.

\section{CONCLUSIONES}

a) El Poder Ejecutivo acelera la trasformación digital del Estado para hacer frente a la pandemia producida por la COVID-19, dado que las entidades estatales tienen la obligación de convertir los procedimientos a servicios digitales hasta finales del presente año.

b) La no actuación oportuna y eficiente frente al panorama del control de la COVID-19 ha originado el cierre de sedes del Poder Judicial e incluso se ha dado el contagio dentro de sedes de diversos distritos judiciales, el trabajo remoto es la nueva forma de trabajo en el cuidado de la salud tanto del personal jurisdiccional como administrativo y de los litigantes.

c) Se ha aprobado el uso del trabajo remoto durante la vigencia del período de emergencia; sin embargo, es una excelente 
oportunidad para la continua modernización del despacho judicial en forma eficaz y transparente y de la administración de justicia no solo en beneficio de la sociedad, sino al cuidado del medio ambiente, pues a través de la digitalización de los procesos, en un futuro, se podrá hacer uso del teletrabajo y el Expediente Judicial Electrónico.

d) Sin transgredir las normas dictadas por el Poder Ejecutivo, la Superintendencia de Banca y Seguros y el Poder Judicial, se reinician paulatinamente las actividades económicas en aplicación de normas establecidas en el Código Civil y el Código Procesal Civil; además, se establecieron las acciones de acuerdo con los procesos no urgentes.

e) El protocolo aprobado es de implementación progresiva y permanente, sujeto a perfeccionamiento, en tanto se habiliten los medios tecnológicos suficientes, y puede ser usado como una buena práctica jurisdiccional con réplica a todos los distritos judiciales del país que no tengan implementado el Expediente Judicial Electrónico.

f) La aprobación del Protocolo de Actuación de Trabajo Remoto en el Módulo Corporativo de los Juzgados de Paz Letrado Civil Comercial de la Corte Superior de Justicia de La Libertad (CSJLL) durante el estado de emergencia nacional, a consecuencia del brote del coronavirus (COVID-19) en el Perú y su aplicación continua, ha logrado retos de coordinación interinstitucional, como remitir los primeros partes digitales coordinando con la Policía Nacional del Perú, el Reniec y las municipalidades de otros departamentos y provincias alejadas.

g) El Consejo Ejecutivo, mediante la Resolución Administrativa n. ${ }^{\circ}$ 00156-2020-CE-PJ, de fecha 23 de mayo de 2020, ha establecido la validez de los actos procesales que realizan los órganos jurisdiccionales de los distritos judiciales del país, distintos a 
los órganos jurisdiccionales de emergencia, por acceso remoto. Este es un plan viable que puede replicarse en todos los distritos judiciales del Perú.

\section{REFERENCIAS}

De Carlo, S. (10 de agosto de 2017). How the Remote Landscape Is Changing. Recuperado de https://www.nomadcity.org/howthe-remote-landscape-is-changing/

Jonay, C. (septiembre, 2018). Conferencia sobre trabajo remoto: Nomad City 2018. Economía TIC. Recuperado de https://economiatic. com/conferencia-trabajo-remoto/

Ministerio de Justicia y Derechos Humanos (1993). Resolución Ministerial n. ${ }^{\circ}$ 10-93-JUS. Texto Único Ordenado del Código Procesal Civil. Lima: 8 de enero de 1993.

Ministerio de Salud (25 de mayo de 2020). Cifras actualizadas al 25 de mayo del 2020. Recuperado de Perú en tus manos.

Ministerio de Trabajo y Promoción del Empleo (2020). Guía para la aplicación del trabajo remoto. Recuperado de https://cdn.www. gob.pe/uploads/document/file/571631/GUIA_PARA_LA_ APLICACION_DEL_TRABAJO_REMOTO.pdf

Poder Judicial (2014). Resolución Administrativa n. ${ }^{\circ}$ 10-2014-CE-PJ. Lima: 7 de enero de 2014.

(2018). Resolución Administrativa n. $^{\circ}$ 090-2018-CE-PJ. Lima: 14 de marzo de 2018.

(2020a). Resolución Administrativa n. ${ }^{\circ}$ 103-2020-CE-PJ. Lima: 11 de marzo de 2020.

(2020b). Resolución Administrativa n. ${ }^{\circ}$ 121-2020-CE-PJ. Lima: 17 de abril de 2020 .

(2020c). Resolución Administrativa n. ${ }^{0}$ 156-2020-CE-PJ. Lima: 23 de mayo de 2020. 
Rothe, C., Schunk, M. et al. (marzo, 2020). Transmisión de la infección 2019-nCoV desde un contacto asintomático en Alemania. The New England Journal of Medicine, (382), 970-971.

Superintendencia Nacional de Registros Públicos (Sunarp) (2019a). Resolución del Superintendente Nacional de los Registros Públicos n. ${ }^{\circ}$ 120-2019-Sunarp/SN. Directiva que regula el Sistema de Intermediación Digital de la Sunarp para la generación, presentación, trámite e inscripción del Título Electrónico ante el registro Lima: 27 de mayo de 2019.

(2019b). Resolución del Superintendente Nacional de los Registros Públicos n. ${ }^{\circ}$ 240-2019-Sunarp/SN. Directiva que regula la presentación, trámite e inscripción del título conformado por el parte judicial con firma digital sobre medidas cautelares. Lima: 18 de septiembre de 2019.

Trilla, A. (marzo, 2020). Un mundo, una salud: la epidemia por el nuevo coronavirus COVID-19. Medicina Clínica 154(5), 175-177. Recuperado de https://www.elsevier.es/es-revistamedicina-clinica-2-avance-resumen-un-mundo-una-saludepidemia-S002577532030141X 